\title{
Mostos y Tabancos. Espacios de sociabilidad en la cultura tradicional jerezana
}

Pilar Zafra Costán, Centro de Documentación del IAPH

Sabor a tierra y tradición, olor a raíces, a tierra labrada, a entronques, a viejos palos que se celebran, se actualizan en cada trago, en cada encuentro, con cada pique, en cada arranque... Banderas rojas ondean al pie de los caminos de las casas de viña que jalonan los viñedos de la campiña jerezana, se perfilan sobre el fondo verde del dintel de los viejos tabancos que aún perviven en el entramado de la ciudad donde se bailaba "el jaleo de Jerez". El nuevo mosto da pie a una vida social intensa bien adentrado el otoño y en las puertas del invierno; su llegada se celebra como arcaico festejo que amaina los primeros fríos.

Encajado entre el mar y la montaña, entre las vegas del río Guadalete, las marismas y los pastizales, un paisaje de horizontes abiertos de albariza, modelado por la alternancia de cultivos de secano y viñedos, por la impronta de añejos modelos latifundarios, por el trabajo de braceros a tiempo... dibuja el perfil de la campiña gaditana a su paso por Jerez.

Encrucijada histórica de caminos de ida y vuelta entre Cádiz y Sevilla, Jerez de la Frontera hace del binomio vino y flamenco un dualismo mágico, una combinación que lleva a sus límites en los distintos espacios de representación que definen su entramado urbano y antropizan su paisaje.

Antes de que la riqueza y diversidad de determinados fenómenos culturales fuese difundida de forma global e incluso ensalzada convenientemente por el tópico o la reiteración por la inmensa potencia de los medios de comunicación, los rasgos esenciales de aquellas realidades culturales se tornaban más nítidos y especialmente los referidos a sus vínculos con un territorio, con el espacio concreto en los que se fraguó. Culturas como la vitivinicola y expresiones tan relevantes como el flamenco, insertas en un marco como el que perfila la campiña gaditana de Jerez, conforman un hecho cultural inexplicable fuera de los límites que establece su condición territorial, una triada que se marida a partir de una determinada condición social, económica y cultural que se ha ido vertebrando al compás del paso del tiempo, proyectándose en su fisonomia, sus específicas formas expresivas y modos de vida.

Esa estrecha relación entre la actividad productiva y las manifestaciones culturales en Jerez se torna como un fenómeno perceptible desde muy diferentes escalas. Un universo omnipresente en su condición de gran pueblo, cuya apariencia le acerca a lo urbano en la misma medida que sus actividades lo definen como rural, en las edificaciones agrarias que determinan su paisaje vitivinícola o en la importante arquitectura bodeguera que afecta directamente a su entramado. Sin embargo, es en las antiguas ventas de las afueras, en las muchas casas de viña, que con el nacimiento del nuevo mosto abren sus puertas para dispensar comida y trago, o en el devenir cotidiano de los modestos tabancos que aún sobreviven en barrios como el de Santiago o San Miguel, donde esta vinculación entre vino y flamenco ha de entenderse como parte fundamental de los rituales de convivencia.

Es en los tabancos y mostos, en estos reductos intimos de vecindad, donde vino y flamenco encuentran su eje, porque más allá de los clichés impuestos estos espacios de encuentro rezuman un trasfondo de realidad humana, de buscarse la vida, de compartirla, de cantarla. Sin más acompañamiento que las palmas, los pitos, los nudillos sobre el mostrador, el cante se alterna con la conversación, el chiste, el comentario, dentro de un elevado grado de comunicación interpersonal, transmisión, tensión y provocación emocional que suele ser aderezado con el lubricante social del vino, que ha procurado las mejores horas de convivencia y ha dado al cante su soplo orgiástico. Baste recorrer sus calles o los caminos que jalonan sus campos para percatarse de que en Jerez esto no es un hecho aislado.

Estos espacios han ser entendidos como referentes de la identidad social, preferentemente masculina, que definen experiencias, actitudes y comportamientos; como espacios, en suma, de ritualización, de interrelación, transmisión social y formación de grupo que, en el caso de los tabancos, han ido languideciendo, llegando 

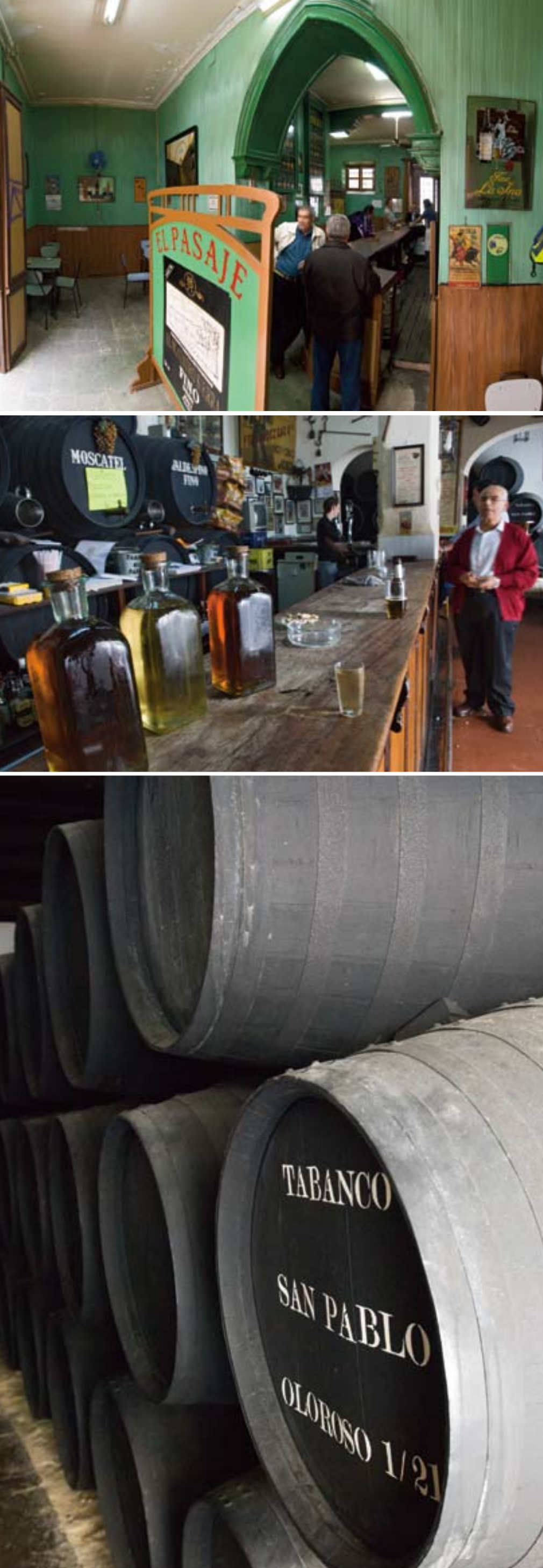

a desaparecer en su mayoría, pero que también forman parte de la historia y cultura jerezana.

Los contrastes sucesivos que infunde el trazado urbano de Jerez le confieren una fisonomía personal, complementada por la arquitectura de sus cascos de bodegas, desde los que emergen exultantes aromas de vinos para cristalizarse con el acervo cultural que destilan barrios tan representativos como los de Santiago o San Miguel, claves en la geografía del flamenco por ser cuna y cantera de cantes y grandes creadores e intérpretes de lo jondo.

Insertos en pleno corazón de estos barrios, perduran apenas algunos ejemplos testimoniales de uno de los referentes más importantes en la cultura popular jerezana, de tanta importancia en el consumo interior de vinos: los tabancos. Establecimientos tradicionales muy masculinizados que servían para vender vino en la propia ciudad y que en Jerez nada tienen que ver con la definición que reciben en los distintos diccionarios como puesto de venta ambulante o callejera, porque si algo caracteriza al tabanco es su vocación de taberna, de pequeño rincón bodeguero donde se escanciaba vino de varias botas, chicas o medianas, dispuestas en segunda o tercera.

Como el Pasaje de la calle Santa María, uno de los pocos que quedan en la ciudad, eran los tabancos jerezanos locales espaciosos. De techo alto de viguería vista y antaño de suelo terrizo cubierto de arena de canto amarillo. Tenían un amplio mostrador, tras el cual se alzaba un cachón o pequeña andana de botas. Pocas mesas y varias sillas de anea. El tabanco era un local popular donde se despachaba, para calmar la sed del parroquiano, directamente de los barriles a chorro de canilla, buen fino y vino oloroso.

Fue el templo de la iglesia parroquial de San Miguel, como el de Santiago, el punto de partida del asentamiento de familias flamencas que darian origen al popular barrio de La Plazuela. En sus cercanías aún abre sus puertas el Tabanco San Pablo, testimonio de aquellas tascas donde sólo se servía vino recio en dosis de a medio tapón y se cantaban las penas. Fueron establecimientos claves en la gestación de los mejores cantes y es de los pocos que se conservan a la antigua usanza.

Como expresión cultural, el flamenco no es un elemento único y representativo de Jerez de la Frontera; sin embargo, es posible afirmar que en esta localidad gaditana adquiere una especial significación nada azarosa. El motivo reside en que, fundamentalmente en lo ambiental y lo social, en el Jerez de antaño se hallaban unidas dos maneras de vida y trabajo: la del campo o la viña y la de la bodega. Junto a las reuniones familiares, bodas y bautizos, en los patios o en

Tabanco El Pasaje. Calles Santa María y Mesones (Jerez de la Frontera, Cádiz). Foto: Juan Carlos Cazalla, IAPH

Tabanco San Pablo, emplazado en la calle del mismo nombre (Jerez de la Frontera, Cádiz). Foto: Juan Carlos Cazalla, IAPH

Andana de botas. Tabanco San Pablo, emplazado en la calle del mismo nombre (Jerez de la Frontera, Cádiz). Foto: Juan Carlos Cazalla, IAPH 
los largos atardeceres campesinos de los almijares, el cante en Jerez hay que situarlo en ese convivir de hombres del vino, en la reunión de amigos en el tabanco del barrio al término de la tarea.

Los tabancos, que con el paso del tiempo han ido desapareciendo siendo su presencia tan sólo testimonial en la actualidad, componen verdaderos espacios de flamenco. Sin horarios ni fechas concretas, estos lugares constituian la voz de un pueblo que escenificaba cantando y bailando sentimientos, experiencias y anhelos.

Jerez se desdibuja a medida que el paisaje impone su presencia en su salida hacia Trebujena. Lo urbano da paso a un paisaje cuajado de viñedos, sobre cuyos altozanos dominan los tradicionales caserios de viña. Casi siempre encalados y de factura sobria en lo decorativo, sus blancos volúmenes se erigen sobre la zona más elevada del terreno, al objeto de obtener desde ellas una visión panorámica de sus pagos.

Dicen que "por san Andrés el mosto vino es" y es que con la llegada de los fríos invernales que anuncian el mes de diciembre muchas de aquellas casas de viña que peinan la campiña jerezana se visten de rojo indicando con banderolas al pie de cada senda que ya hay mosto en las despensas.

Es justo el tiempo en que los caminos hacia Trebujena comienzan a ser más transitados que de costumbre; el Jerez joven acaba de nacer. Mostos como el de El Domi abren sus puertas para acoger a los numerosos parroquianos que hasta la llegada de la primavera acompañarán cada trago de un buen plato de ajo campero o berza, convirtiendo la reunión en torno al mosto más en un ritual que en un simple almuerzo de domingo. Comida de jornaleros y bebida de trabajadores. Pequeñas casas de viña, como la de El Carmen, que tantos quehaceres y fatigas acogieron, han sido testigos de más afanes: albergaron la pausa del trabajo, sueños y desvelos, tratos y transacciones de todo género de la gente de campo. Con el flamenco como compañero de fatigas, han compartido risas y sudores, constituyendo un espacio ineludible de la sociabilidad jerezana. Durante los minutos de descanso de la jornada, estas fuentes de tradición daban la cara.

Hasta mediados del siglo XIX, Jerez se encontraba rodeado de viñedos que ocupaban la mayor parte de las tierras de labor junto a cereales y olivos. La plaga de filoxera provocó que parte de las vides fueran sustituidas por otros cultivos que vinieron a enriquecer el horizonte de la campiña de Jerez. Sin embargo, la significación patrimonial y cultural que introduce este paisaje revela la histórica relación de los jerezanos con su territorio. La

Viña El Carmen (Jerez de la Frontera, Cádiz). Foto: Juan Carlos Cazalla, IAPH Paisaje de viñedos (Jerez de la Frontera, Cádiz). Foto: Juan Carlos Cazalla, IAPH
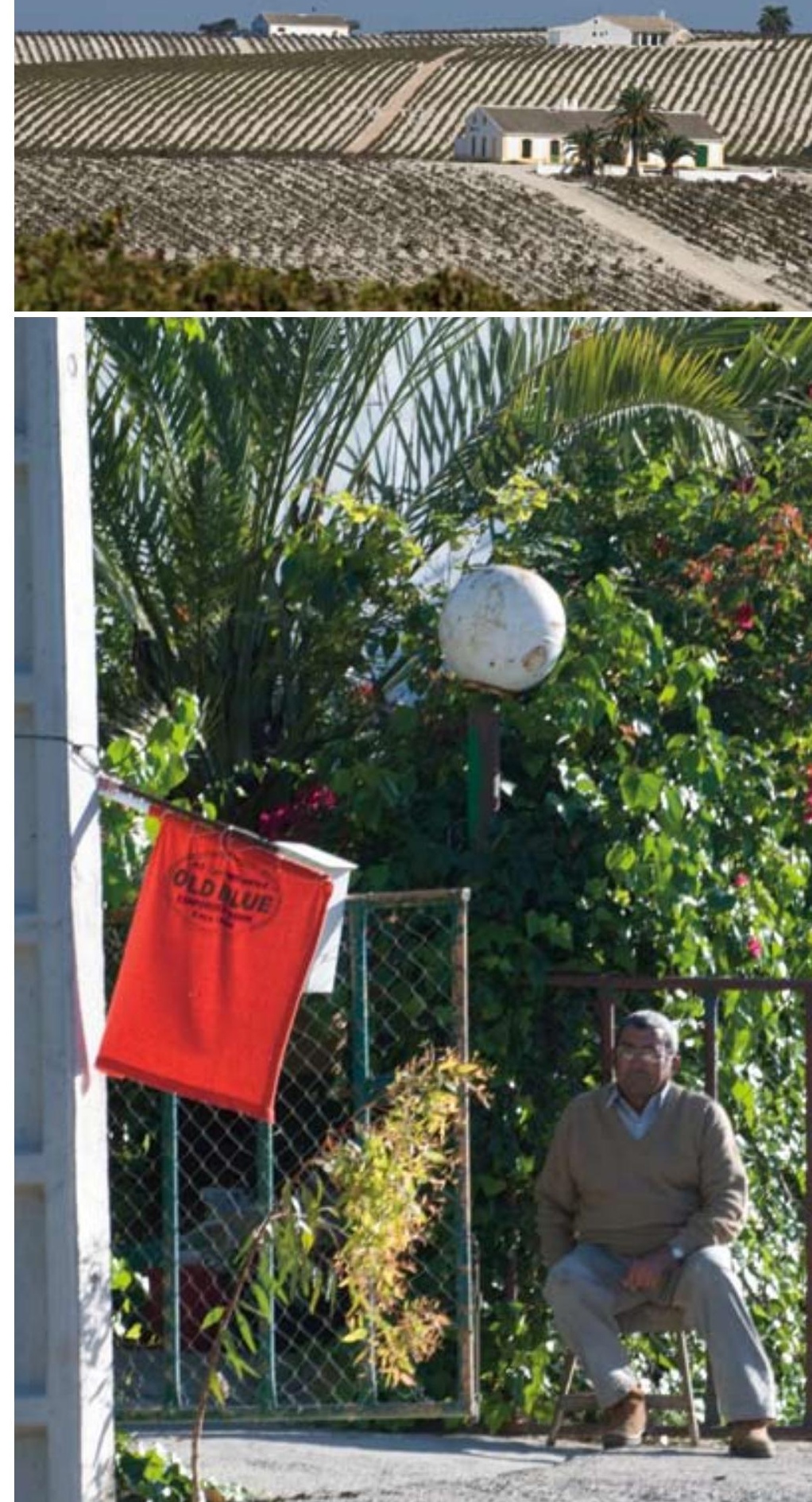

cultura del vino ha sido sin duda un elemento fundamental del tejido cultural jerezano, popular tanto por su consumo como por su presencia física, económica y olfativa. Pero no sólo el viñedo fragua el terreno, sino también las edificaciones agrarias vinculadas con este sistema de aprovechamiento, que contemplan el espacio construido hasta hacerlo lugar de vida. Casas de viña como San Cayetano, probablemente de mediados del siglo XIX, definen la arquitectura caracteristica del viñedo de Jerez. Una estructura rectangular, de factura simple de cubierta a dos aguas de teja árabe, que apoya a modo de faldón sobre un pórtico adintelado de gran plasticidad, revela la distribución habitual de estas construcciones: desde el zaguán, que cerraba la explanada del almijar, se accedia a la vivienda del propietario, a la cuadra y al lagar, que permitía el paso al resto de habitaciones. Destinadas en origen a la obtención de mosto o zumo de uva y determinadas por la presencia del lagar como pieza esencial de su funcionamiento, desde hace cuarenta años a esta parte han visto tornar sus funciones, convirtiendo en venta lo que en su día constituyeron estos espacios productivos tradicionales tan singulares dentro de la campiña gaditana.

Mostos como El Corregidor Viejo, se han erigido a lo largo del tiempo en escenario rural único de relaciones humanas. No se puede echar una mirada atrás en el pasado más reciente sin tenerlos en cuenta porque no sólo son historia, son una realidad llena de vitalidad que se cotiza en el mercado de tiempo libre de los gaditanos.

Mostos y tabancos jerezanos, de carácter tremendamente popular, se han perfilado como uno de los escenarios naturales de la sociabilidad jerezana. Durante su existencia no sólo han calmado los ánimos de parroquianos y forasteros despachando vino de la tierra y viandas, sino que han albergado la vida y han visto germinar el arte. Sabia de gitaneria, de tertulias, de cante y baile, pueden haber despachado insomnios pero han generado sueños prodigados al amor de la candela de inmensas chimeneas y de un tablao.

\section{Bibliografía}

ALADRO PRIETO, José Manuel. Algunas claves para la comprensión del paisaje rural del viñedo del marco de Jerez. Revista de historia y teoría de la arquitectu$r a, n^{\circ} 2-3,2002$, p. 260-273 *

ALADRO PRIETO, José Manuel. Paisaje, Memoria y Patrimonio, claves para el entendimiento patrimonial del paisaje vitícola jerezano. En: I Congreso Internacional "Patrimonio, Desarrollo Rural y Turismo en el Siglo XXI" (Osuna, 20-22 octubre 2004). Sevilla : Universidad de Sevilla, 2004, p. 21-31

ARCHIVO MUNICIPAL DE MEDINA SIDONIA. Inventario del Archivo Municipal de Medina Sidonia / Victoria Martín Mila, Francisca Ruano Fernández. Cádiz : Diputación Provincial de Cádiz, 1992

ASOCIACIÓN INTERNACIONAL DE HISTORIA Y CIVILIZACIÓN DE LA VID Y EL VINO. SIMPOSIO (1. 1999. El Puerto de Santa Maria). Actas del I Simposio de la Asociación Internacional de Historia y Civilización de la Vid y el Vino / Javier Maldonado Rosso (ed.). El Puerto de Santa María : Asociación Internacional de Historia y Civilización de la Vid y el Vino : Ayuntamiento de El Puerto de Santa María, 2001, 2 v. *

CORTIJOS, haciendas y lagares : arquitectura de las grandes explotaciones agrarias de Andalucía : provincia de Cádiz. [Sevilla] : Consejería de Obras Públicas y Transportes, Dirección General de Arquitectura y Vivienda, 2002 * cossío, José María de; DíAZ CAÑABATE, Antonio. Los toros : tratado técnico e histórico. Madrid : Espasa Calpe, 1943-1997

DELGADO POULLET, José. Casas de viña de El Puerto y Jerez. En: Actas de las VI Jornadas del vino fino. El Puerto de Santa María : Ayuntamiento, D.L. 2001

DURÁN SALADO, Maria Isabel. La otra banda : Sanlúcar de Barrameda en la territorialización de Doñana : siglos XIV-XX. [Sevilla] : Junta de Andalucía, Consejería de Cultura, D.L. 2003 *

ESPAÑOL ECHÁNIZ, Ignacio. Carretera y paisaje : recomendaciones para la gestión y mejora del paisaje de la carretera. Madrid: Ministerio de Fomento, 2008

GÓMEZ DİAZ, Ana María. La manzanilla : historia y cultura, las bodegas de Sanlúcar. Sanlúcar de Barrameda : Pequeñas Ideas Editoriales, [2002]

IGLESIAS RODRÍGUEZ, Juan José (ed.). Historia y cultura del vino en Andalucía. Sevilla : Universidad de Sevilla, Secretariado de Publicaciones, 1995 *

MALDONADO ROSSO, Javier...[et al.]. Añadas y soleras : catálogo de la exposición sobre los vinos, vinagres, aguardientes y licores de la provincia de Cádiz = Añadas \&t soleras : catalogue for the exhibition about wines, vinegars, spirits and liquors in Cádiz district. Cádiz : Diputación de Cádiz, 1997 *
MALDONADO ROSSO, Javier [et al.]. Manual Patrivit para la localización y catalogación del patrimonio vitícola mueble e histórico. El Puerto de Santa María : Ayuntamiento de El Puerto de Santa María, Area de Fomento, $1997^{*}$

MARCOS ARÉVALO, Javier (ed.). Las culturas del vino : del cultivo y la producción a la sociabilidad en el beber. Sevilla : Signatura, 2005 *

MUSEO ARQUEOLÓGICO MUNICIPAL DE JEREZ DE LA FRONTERA. Museo Arqueológico Municipal [de] Jerez de la Frontera. Jerez: Servicio de Publicaciones del Ayuntamiento, D.L.1997*

PLATA, Juan de la. Los tabancos y ventas de Jerez : antiguas tiendas de montañeses, grandes cafés y viejos bares, cervecerías, cabarets y salones de baile. Jerez de la Frontera : Ediciones Cofrán, D.L. 2003

SOTELINO, Manuel. Cádiz Bravo : un recorrido por las ganaderías y las familias ganaderas del toro bravo en Cádiz. Jerez : Publicaciones del Sur, 2004

Nota: Bibliografia resumida de la sección. Para una mayor información puede dirigirse a la Biblioteca del IAPH. Las publicaciones marcadas con asterisco ${ }^{*}$ ) se encuentran disponibles para su consulta en la Biblioteca del IAPH. 